\title{
Employee Incentive Program: Its Role in Enhancing Employee Performance, in Selected Companies in Kingdom of Bahrain
}

\author{
Dr Marluna Lim Urubio \\ Planning and Development Director, Faculty - College of Administrative and Financial Sciences, \\ AMA International University Bahrain, Kingdom of Bahrain \\ Member, Bahrain Management Society \\ Member, Philippine Institute of Industrial Engineers
}

\begin{abstract}
The research is about the role of incentive program on employee performance. These incentive programs refer to the financial and non financial incentives. This has been done to assess how these types of rewards can have positive effects or influence the quality of work, quantity of work, attendance and punctuality, work behavior and cooperation. The methodology used to facilitate the research included descriptive - evaluative approach in order to answer the questions posted in the statement of the problems. The main tool for the data gathering and collection in this research was the questionnaire which was designed and validated by the researcher. Unstructured interviews were conducted to get more information, which supplemented the responses gathered through the use of the questionnaire. The results of the research showed that both the financial and non financial are appreciated by the respondents, in fact they all agreed on the contribution of these to the different performance criteria. However, it was very clear on the correlation that financial rewards are valued more by the respondents to have a much stronger effect on the employee performance.
\end{abstract}

Keywords: financial incentive, non financial incentive, quality of work, quantity of work, performance criteria.

\section{INTRODUCTION}

Every individual needs some form of motivation so that he will be more inspired to work [1]. Many successful companies acknowledge that the most important asset of the organization is its people. However, people only become the best and most important asset of the organization if the employees are functioning effectively and exhibiting a high performance level.

Employee performance is a combination of ability and motivation[2]. Ability is derived from having the necessary knowledge, skills, training and resources in doing the job while motivation is derived from the work environment. Motivation is the inner force that drives the person to perform well or even more than what is expected [3].

Giving that inner drive to employees is called motivation and this comes in 2 forms, financial and non financial motivation $[4,5]$. There are early theories of motivation which have been used as basis to motivate employees. These are the Maslow's Hierarchy of Needs, McGregor's Theory $\mathrm{X}$ and $\mathrm{Y}$, Herzberg's 2 Factor Theory and Mc Cleland 3 Need's theory [6]. Motivations come in different forms. It could be in terms of financial or non financial that can affect every employee's performance.

This research intends to study the role of incentive program in enhancing employee performance in selected organizations in the Kingdom of Bahrain. Specifically, it intends to answer the following questions:

1. What is the general perception of the respondents on the incentive program in enhancing employee performance when grouped according to profile?

2. What is the perceived role of non-financial incentive program in enhancing employee performance when grouped according to profile?

3. What is the perceived role of financial incentive program in enhancing employee performance when grouped according to profile?

4. What is the relationship of incentive program and employee performance?

The following objectives that are expected to be met after the conduct of this research:

1. To know the general perception of the respondents on the incentive program in enhancing employee performance,

2. To understand the perceived role of non-financial incentive program in enhancing employee performance.

3. To see the perceived role of financial incentive program in enhancing employee performance.

4. To check whether there is a relationship between incentive program and employee performance? 


\section{RESEARCH METHODOLOGY}

Since the main objective of this research is to find the role of incentive program in enhancing employee performance in selected companies in the Kingdom of Bahrain, therefore this research used descriptive - evaluative approach. Respondents who are Human Resource Managers and Supervisors of different companies in Bahrain are to be given questionnaires which will be collected later in a specified date.

\section{Results and Discussion}

1. On the general perception of respondents on the incentive program based on their profile.

1.1. Both male and female respondents have similar responses shown in Table 1 (4.51)which is "strongly agree "when asked about whether financial incentives improve their quality and quantity of work, behaviour such as commitment, volunteerism among others.

1.2 General perception based on the age group of the respondent in Table 2showed a "strongly agree response (4.53)when asked about behavior, commitment, volunteerism, improving quality of work as a result of financial incentive.

1.3 Respondents grouped according to their highest academic qualification in Table 3 somewhat agreed (4.35) agreed on the role of incentive program in enhancing employee performance.

1.4 Both supervisory and managerial level in Table 4 ( 4.51)strongly agreed that motivation and behaviour are influenced by financial incentives.

1.5 Regardless of the number of years (Table 5) they have worked with the company, the respondents strongly agreed (4.60) that employees are motivated with financial incentives given to them.

1.6 Respondents are grouped based on the size of the company in Table 6, and strongly agreed (4.55) that employees are motivated to improve their quality and quantity of work as well as their behavior in terms of commitment and volunteerism when there is financial incentives specifically money.

1.7 Respondents grouped based on the departments ( Table 7) they are working for strongly agreed (4.52) that financial incentives motivate them to exhibit commitment and volunteerism at work.

2. Statement of the problem No. is the perceived role of non-financial incentive program in enhancing employee performance, the following are the results.

2.1 Respondents when grouped according to Sex or Gender in Table 8 believed that non financial incentives have tremendous contribution (4.84) to their performance

2.2 Respondents grouped by age in Table 9 have viewed non financial incentive program to have tremendous (4.82) contribution on the performance criteria mentioned except for the work behavior

2.3 Respondents grouped by their educational background in Table 10 have viewed non financial incentive program as having tremendous contribution (4.84) to their performance.

2.4 Respondents grouped by the position in Table 11 have viewed non financial incentive program to have tremendous contribution (4.84) to their performance.

2.5 Respondents grouped by the number of years in Table 12 believed on the tremendous contribution (4.86)of non financial incentive program in relation their performance at work.

2.6 Respondents were also grouped by size of the company in Table 13 and they believed on the tremendous contribution (4.85) of non financial incentives to their performance.

3. Statement of the Problem No 3 is the perceived role of financial incentive program in enhancing employee performance.

3.1 Respondents grouped into gender in Table 14, stated that financial incentive program have a moderate contribution (3.00) to the 5 performance criteria .

3.2 In Table 15, respondents grouped by age showed also that they only see a moderate contribution (3.00) of the financial incentive program in improving quality and quantity of work, punctuality and attendance, work behaviour and cooperation.

3.3 Table 16 shows the result when respondents are grouped according to educational background. The 2 groups also rated financial incentive program to have only a moderate contribution to the 5 performance criteria.

3.4 For Table 17, respondents are grouped by position and they view financial incentive program to have a moderate contribution to the 5 performance criteria.

3.5 Table 18 shows the respondents were grouped as to the number of years they have worked with the company and they have viewed financial incentive program to have little contribution in enhancing their performance.

3.6 Table 19 shows the result when respondents grouped according to the size of the company and they said that financial incentives have tremendous contribution

4.The data for the Statement of the Problem No 4 which is about the relationship of Incentive Program and Employee Performance is shown in Table 20.

The data as shown in the Table 20 below are the Pearson r-test results on the relationship of employee performance and the respondents' affordances of their perception in terms of the general incentive program, financial and non financial incentive program.

From the result, it is shown that respondents do not show relationship of non financial incentives to their performance. The apparent lack of relationship of non financial incentive and performance can be explained by this: In some situation, incentive programs whether financial or non financial will not work well to effect an improved performance. There are reasons for that like (a) no matter what incentive is given the employee simply 
does not possess the capacity to perform the task of excellence, are available so that employees would not exceptionally. It can be concluded that the employee does be frustrated not being able to perform well and get not possess the required knowledge or skill so that the task incentives due to company's mistake.

can be done (b) there are no materials or tools and equipment or any other resources available so that he can perform the task. For these reasons, not any incentive can give a link to the desired performance [38].

\section{REFERENCES}

\section{III.CONCLUSION}

Below are the summary of conclusions based from the findings:

Respondents believe that both financial and non financial incentive enhances employee performance.

On the perceived role of non-financial incentive program in enhancing employee performance, respondents although they do not see that non financial incentives are influencing their performance, but they are appreciative of the different non financial incentives given to them.

The financial incentive program is seen to just have moderate contribution in enhancing employee performance.

On whether there is a relationship between incentive program and employee performance, it is concluded that it is not money alone or financial incentives that make employees happy and motivated to work.

\section{Summary of Recommendations.}

1.Financial incentives, should be sustained and be clear with the criteria on how employees will be able to get it. For non financial incentives, same is true, criteria should be clear so as not to create animosity and confusion which could later result to conflict.

2.On the perceived role of non-financial incentive program in enhancing employee performance. It is recommended that companies should reflect how recognition and appreciation can be given in a manner that will be most treasured by the employees.

3 For financial incentive program, there should be sustainability and clarity of criteria for financial incentive, and companies should consider giving intrinsic motivation.

4.On the relationship between incentive program and employee performance, it is recommended that if possible companies should couple the non financial incentive program with the financial incentives. As given in the previous discussion, the company should ensure that employees possess the necessary knowledge and skills on the job to give everyone within the organization equal opportunity to get the incentives. The companies should also ensure that all resources needed to perform high level

[1] Michael Kirstein, ( 2010 ) The Role of Motivation In Human Resource Management : Importance of Motivation Factors among Future Business Persons.

[2] Condly, S.J, Clark R.E et al, ( 2003), The Effects of Incentives on Workplace Performance: A Meta-review of Research Studies. Performance Improvement Quarterly.

[3] Cameron J and Pierce W.D ( 2006 ) Rewards and Intrinsic Motivation: Resolving the Controversy. United State: Bergin and Garvay.

[4] David Hume, ( 1995 ) Reward Management: Employee performance Motivation and Pay ( Human Resource Management in Action )

[5] Momina Giranaz, ( 2010 ) Job satisfaction; Impact of Non Financial Incentives on Job Satisfaction.

[6] John Shields and Michelle Brown, ( 2015 ) Managing Employee Performance and Rewards : Concepts, Practices and Strategies.

[7] William Stevenson, (2011) Operations Management, $11^{\text {th }}$ Edition, Published by Mc Graw Hill, ISBN-13-978-0073525259

[8] Jay Heizer and Barry Render, (2010) Operations Management , $10^{\text {th }}$ Edition, Published by Prentice Hall, ISBN 13-978-0132163927

[9] Robbins and Coulter, 2010 , Management, $11^{\text {th }}$ Edition

[10] Robert Lavigna, ( 2013 ) Engaging Government Employees: Motivate and Inspire Your People to Achieve Superior Performance.

[11] Jeffrey S and Shaffer V. ( 2007 ) The Motivational Properties of Tangible Incentives. Compensation and Benefits Review.

[12] Mohammad Atiqur and Mariam Jabbour, ( 2012 ), Employee Motivation through Non Financial Incentives: A Case Study from the UK.

[13] Armstrong M ( 2001 ) Employee reward Management and Practice, London and Philadelphia; Kogan Page

[14] Essi Huttu, The Effects of Incentives on Performance and Job Satisfaction, Temper University of Technology

[15] Calista Lai, ( 2009 )Motivating Employees Through Incentive Program, Jyvaskyla University of Applied Science.

[16] Marlisa Abdul Rahim and Wan Norhayate Wan Daud ( 2012 ) Proposed Conceptual Framework for Rewards and Motivation among Administrators of Higher Educational Provider in Malaysia, International Journal of Business Commerce.

[17]. Sarah E. Bonner, Reid Hastie, Geoffrey B. Sprinkle, and S. Mark Young (2000) A Review of the Effects of Financial Incentives on Performance in Laboratory Tasks: Implications for Management Accounting. Journal of Management Accounting Research: December 2000, Vol. 12, No. 1, pp. 19-64.

[18]. Roland, Martin; Dudley, R. Adams. How Financial and Reputational Incentives Can Be Used to Improve Medical Care. Health Services Research. Dec2015 Supplement, Vol. 50, p20902115. 26p. 2 Charts. DOI: $10.1111 / 1475-6773.12419$. AMAIUB Lib

[19]. Garbers, Yvonne and Konradt, Udo, The effect of financial incentives on performance: A quantitative review of individual and team-based financial incentives, Journal of Occupational \& Organizational Psychology. Mar2014, Vol. 87 Issue 1, p102-137, AMAIUB Lib

[20]. Läpple, Doris; Hennessy, Thia. Assessing the Impact of Financial Incentives in Extension Programmes: Evidence From Ireland. „Journal of Agricultural Economics. Sep2015, Vol. 66 Issue 3, p781-795. 15p. DOI: 10.1111/1477-9552.12108, AMAIUB Lib

[21] Fulbeck, Eleanor S.; Richards, Meredith P. Impact of School-Based Financial Incentives on Teachers' Strategic Moves: A Descriptive Analysis, Teachers College Record. Sep2015, Vol. 117 Issue 9, p136. 36p. AMAIUB Lib 
ISO 3297:2007 Certified

Vol. 4, Issue 3, March 2017

Table 1. General Perception as to Sex

\begin{tabular}{|c|c|c|c|c|}
\hline Indicators & \multicolumn{2}{|c|}{ Male } & \multicolumn{2}{c|}{ Female } \\
\hline & Mean & DI & Mean & DI \\
\hline 1 & 4.68 & StA & 4.81 & StA \\
\hline 2 & 4.47 & SwA & 4.23 & SwA \\
\hline 3 & 4.63 & StA & 4.68 & StA \\
\hline 4 & 4.16 & SwA & 4.55 & StA \\
\hline 5 & 4.68 & StA & 4.48 & SwA \\
\hline 6 & 4.58 & StA & 4.58 & StA \\
\hline 7 & 4.68 & StA & 4.68 & StA \\
\hline 8 & 4.32 & SwA & 4.39 & SwA \\
\hline 9 & 4.47 & SwA & 4.52 & StA \\
\hline 10 & 4.68 & StA & 4.45 & SwA \\
\hline 11 & 4.37 & SwA & 4.55 & StA \\
\hline 12 & 4.26 & SwA & 4.42 & SwA \\
\hline Average & 4.500 & StA & 4.527 & StA \\
\hline
\end{tabular}

Legend: SwA - Somewhat Agree; StA - Strongly Agree

Table 2. General Perceptions as to Age

\begin{tabular}{|c|c|c|c|c|c|c|}
\hline Indicators & \multicolumn{2}{|c|}{$26-35$} & \multicolumn{2}{c|}{$36-45$} & \multicolumn{2}{c|}{$46-55$} \\
\hline & Mean & DI & Mean & DI & Mean & DI \\
\hline 1 & 4.89 & StA & 4.72 & StA & 4.75 & StA \\
\hline 2 & 4.22 & SwA & 4.28 & SwA & 4.44 & SwA \\
\hline 3 & 4.56 & StA & 4.68 & StA & 4.69 & StA \\
\hline 4 & 4.78 & StA & 4.32 & SwA & 4.31 & SwA \\
\hline 5 & 4.67 & StA & 4.40 & SwA & 4.75 & StA \\
\hline 6 & 4.67 & StA & 4.40 & SwA & 4.81 & StA \\
\hline 7 & 4.78 & StA & 4.56 & StA & 4.81 & StA \\
\hline 8 & 4.00 & SwA & 4.48 & SwA & 4.38 & SwA \\
\hline 9 & 4.78 & StA & 4.44 & SwA & 4.44 & SwA \\
\hline 10 & 4.33 & SwA & 4.56 & StA & 4.63 & StA \\
\hline 11 & 4.56 & StA & 4.36 & SwA & 4.63 & StA \\
\hline 12 & 4.33 & SwA & 4.32 & SwA & 4.44 & SwA \\
\hline Average & 4.546 & StA & 4.460 & SwA & 4.589 & StA \\
\hline
\end{tabular}

Legend: SwA - Somewhat Agree; StA - Strongly Agree

Table 3. General Perception as to Educational Background

\begin{tabular}{|c|c|c|c|c|}
\hline Indicators & \multicolumn{2}{|c|}{ BS } & \multicolumn{2}{c|}{ MA } \\
\hline & Mean & DI & Mean & DI \\
\hline 1 & 4.84 & StA & 4.63 & StA \\
\hline 2 & 4.32 & SwA & 4.32 & SwA \\
\hline 3 & 4.68 & StA & 4.63 & StA \\
\hline 4 & 4.35 & SwA & 4.47 & SwA \\
\hline 5 & 4.52 & StA & 4.63 & StA \\
\hline 6 & 4.55 & StA & 4.63 & StA \\
\hline 7 & 4.58 & StA & 4.84 & StA \\
\hline 8 & 4.39 & SwA & 4.32 & SwA \\
\hline 9 & 4.52 & StA & 4.47 & SwA \\
\hline 10 & 4.52 & StA & 4.58 & StA \\
\hline 11 & 4.42 & SwA & 4.58 & StA \\
\hline 12 & 4.39 & SwA & 4.32 & SwA \\
\hline Average & 4.505 & StA & 4.535 & StA \\
\hline
\end{tabular}

Legend: SwA - Somewhat Agree; StA - Strongly Agree 


\section{ISO 3297:2007 Certified}

Vol. 4, Issue 3, March 2017

Table 4. General Perception as to Position

\begin{tabular}{|c|c|c|c|c|}
\hline Indicators & \multicolumn{2}{|c|}{ Supervisor } & \multicolumn{2}{c|}{ Manager } \\
\hline & Mean & DI & Mean & DI \\
\hline 1 & 4.76 & StA & 4.76 & StA \\
\hline 2 & 4.31 & SwA & 4.33 & SwA \\
\hline 3 & 4.62 & StA & 4.71 & StA \\
\hline 4 & 4.45 & SwA & 4.33 & SwA \\
\hline 5 & 4.48 & SwA & 5.67 & StA \\
\hline 6 & 4.52 & StA & 4.67 & StA \\
\hline 7 & 4.72 & StA & 4.62 & StA \\
\hline 8 & 4.28 & SwA & 4.48 & SwA \\
\hline 9 & 4.52 & StA & 4.48 & SwA \\
\hline 10 & 4.38 & SwA & 4.76 & StA \\
\hline 11 & 4.55 & StA & 4.38 & SwA \\
\hline 12 & 4.48 & SwA & 4.19 & SwA \\
\hline Average & 4.506 & StA & 4.532 & StA \\
\hline
\end{tabular}

Legend: SwA - Somewhat Agree; StA - Strongly Agree

Table 5. General Perceptions as to Number of Years the respondent has been with the company

\begin{tabular}{|c|c|c|c|c|c|c|}
\hline \multirow{2}{*}{ Indicators } & \multicolumn{2}{|c|}{$1-3$} & \multicolumn{2}{|c|}{$4-6$} & \multicolumn{2}{|c|}{$7-10$} \\
\cline { 2 - 7 } & Mean & DI & Mean & DI & Mean & DI \\
\hline 1 & 5.00 & StA & 4.74 & StA & 4.76 & StA \\
\hline 2 & 4.00 & SwA & 4.35 & SwA & 4.29 & SwA \\
\hline 3 & 5.00 & StA & 4.61 & StA & 4.71 & StA \\
\hline 4 & 4.50 & StA & 4.42 & SwA & 4.35 & SwA \\
\hline 5 & 5.00 & StA & 4.48 & SwA & 4.65 & StA \\
\hline 6 & 5.00 & StA & 4.48 & SwA & 4.71 & StA \\
\hline 7 & 4.50 & StA & 4.68 & StA & 4.71 & StA \\
\hline 8 & 5.00 & StA & 4.29 & SwA & 4.41 & SwA \\
\hline 9 & 5.00 & StA & 4.48 & SwA & 4.47 & SwA \\
\hline 10 & 5.00 & StA & 4.52 & StA & 4.53 & StA \\
\hline 11 & 5.00 & StA & 4.42 & SwA & 4.53 & StA \\
\hline 12 & 4.50 & StA & 4.39 & SwA & 4.29 & SwA \\
\hline Average & 4.792 & SwA & 4.489 & SwA & 4.534 & StA \\
\hline
\end{tabular}

Legend: SwA - Somewhat Agree; StA - Strongly Agree

Table 6. General Perceptions as to Number of Employees

\begin{tabular}{|c|c|c|c|c|c|c|}
\hline Indicators & \multicolumn{2}{|c|}{50 and below } & \multicolumn{2}{c|}{$51-100$} & \multicolumn{2}{c|}{$101-150$} \\
\hline & Mean & DI & Mean & DI & Mean & DI \\
\hline 1 & 4.75 & StA & 4.78 & StA & 4.75 & StA \\
\hline 2 & 4.25 & SwA & 4.33 & SwA & 4.75 & StA \\
\hline 3 & 4.57 & StA & 4.72 & StA & 5.00 & StA \\
\hline 4 & 4.32 & SwA & 4.44 & SwA & 4.75 & StA \\
\hline 5 & 4.43 & SwA & 4.72 & StA & 4.75 & StA \\
\hline 6 & 4.57 & StA & 4.50 & StA & 5.00 & StA \\
\hline 7 & 4.64 & StA & 4.72 & StA & 4.75 & StA \\
\hline 8 & 4.43 & SwA & 4.22 & SwA & 4.50 & StA \\
\hline 9 & 4.43 & SwA & 4.56 & StA & 4.75 & StA \\
\hline 10 & 4.61 & StA & 4.44 & SwA & 4.50 & StA \\
\hline 11 & 4.43 & SwA & 4.50 & StA & 4.75 & StA \\
\hline 12 & 4.39 & SwA & 4.39 & SwA & 4.00 & SwA \\
\hline Average & 4.485 & SwA & 4.528 & StA & 4.688 & StA \\
\hline
\end{tabular}

Legend: SwA - Somewhat Agree; StA - Strongly Agree 
Vol. 4, Issue 3, March 2017

Table 7. General Perception as to Department

\begin{tabular}{|c|c|c|c|c|}
\hline Indicators & \multicolumn{2}{|c|}{ HR } & \multicolumn{2}{c|}{ Operations } \\
\hline & Mean & DI & 4.80 & DI \\
\hline 1 & 4.76 & StA & 4.40 & SwA \\
\hline 2 & 4.31 & SwA & 5.00 & StA \\
\hline 3 & 4.62 & StA & 4.60 & StA \\
\hline 4 & 4.38 & SwA & 4.40 & SwA \\
\hline 5 & 4.58 & StA & 4.80 & StA \\
\hline 6 & 4.56 & StA & 4.40 & SwA \\
\hline 7 & 4.71 & StA & 4.20 & SwA \\
\hline 8 & 4.38 & SwA & 4.60 & StA \\
\hline 10 & 4.49 & SwA & 4.40 & SwA \\
\hline 11 & 4.56 & StA & 4.60 & StA \\
\hline 12 & 4.47 & SwA & 4.20 & SwA \\
\hline Average & 4.38 & SwA & 4.533 & StA \\
\hline
\end{tabular}

Legend: SwA - Somewhat Agree; StA - Strongly Agree

Table 8. Role of Non-financial Incentive Program as to Sex

\begin{tabular}{|l|l|c|c|c|c|}
\hline \multirow{2}{*}{\multicolumn{2}{|c|}{}} & \multicolumn{2}{|c|}{ Male } & \multicolumn{2}{c|}{ Female } \\
\cline { 3 - 6 } & Mean & DI & \multicolumn{2}{c|}{ Mean } & DI \\
\hline 1 & Quality of Work & 4.84 & TC & 4.90 & TC \\
\hline 2 & Quantity of Work & $5.00 \mathrm{a}$ & TC & $5.00 \mathrm{a}$ & TC \\
\hline 3 & Punctuality/attendance & 4.95 & TC & 4.97 & TC \\
\hline 4 & Work Behavior & 4.84 & TC & 4.77 & TC \\
\hline 5 & Cooperation & 4.58 & TC & 4.58 & TC \\
\hline \multicolumn{2}{|l|}{ Average } & 4.842 & TC & 4.845 & TC \\
\hline
\end{tabular}

Legend: TC - Tremendous Contribution

Table 9. Role of Non-financial Incentive Program as to Age

\begin{tabular}{|l|l|c|c|c|c|c|c|}
\hline \multicolumn{2}{|c|}{} & \multicolumn{2}{c|}{$26-35$} & \multicolumn{2}{c|}{$36-45$} & \multicolumn{2}{c|}{$46-55$} \\
\cline { 3 - 8 } & Mean & DI & Mean & DI & Mean & DI \\
\hline 1 & Quality of Work & 4.78 & TC & 4.92 & TC & 4.88 & TC \\
\hline 2 & Quantity of Work & $5.00 \mathrm{a}$ & TC & $5.00 \mathrm{a}$ & TC & $5.00 \mathrm{a}$ & TC \\
\hline 3 & Punctuality/attendance & 5.00 & TC & 4.92 & TC & 5.00 & TC \\
\hline 4 & Work Behavior & 4.67 & TC & 4.80 & TC & 4.88 & TC \\
\hline 5 & Cooperation & 4.44 & CC & 4.64 & TC & 4.56 & TC \\
\hline \multicolumn{2}{|l|l|l|}{ General } & 4.778 & TC & 4.856 & TC & 4.862 & TC \\
\hline
\end{tabular}

Legend: TC Tremendous Contribution; CC - Considerable Contribution

a. $\quad t$ cannot be computed because the standard deviations of both groups are 0

Table 10. Role of Non-financial Incentive Program as to Educational Background

\begin{tabular}{|l|l|c|c|c|c|}
\hline \multicolumn{2}{|c|}{} & \multicolumn{2}{c|}{ BS } & \multicolumn{2}{c|}{ MA } \\
\cline { 3 - 6 } \multicolumn{2}{|c|}{} & Mean & DI & Mean & DI \\
\hline 1 & Quality of Work & 4.90 & TC & 4.84 & TC \\
\hline 2 & Quantity of Work & $5.00 \mathrm{a}$ & TC & $5.00 \mathrm{a}$ & TC \\
\hline 3 & Punctuality/attendance & 4.94 & TC & 5.00 & TC \\
\hline 4 & Work Behavior & 4.77 & TC & 4.84 & TC \\
\hline 5 & Cooperation & 4.58 & TC & 4.58 & TC \\
\hline \multicolumn{2}{|l|}{ Average } & 4.839 & TC & 4.853 & TC \\
\hline
\end{tabular}

Legend: TC - Tremendous Contribution

a. $\quad t$ cannot be computed because the standard deviations of both groups are 0 . 


\section{ISO 3297:2007 Certified}

Vol. 4, Issue 3, March 2017

Table 11. Role of Non-financial Incentive Program as to Position

\begin{tabular}{|l|l|c|c|c|c|}
\hline \multicolumn{2}{|c|}{} & \multicolumn{2}{c|}{ Supervisor } & \multicolumn{2}{c|}{ Manager } \\
\cline { 3 - 6 } \multicolumn{2}{|c|}{} & Mean & DI & Mean & DI \\
\hline 1 & Quality of Work & 4.93 & TC & 4.81 & TC \\
\hline 2 & Quantity of Work & $5.00 \mathrm{a}$ & TC & $5.00 \mathrm{a}$ & TC \\
\hline 3 & Punctuality/attendance & 4.93 & TC & 5.00 & TC \\
\hline 4 & Work Behavior & 4.76 & TC & 4.86 & TC \\
\hline 5 & Cooperation & 4.55 & TC & 4.62 & TC \\
\hline \multicolumn{2}{|l|}{ Average } & 4.834 & TC & 4.857 & TC \\
\hline
\end{tabular}

Legend: TC - Tremendous Contribution t cannot be computed because the standard deviations of both groups are 0.

Table 12. Role of Non-financial Incentive Program as to Number of Years

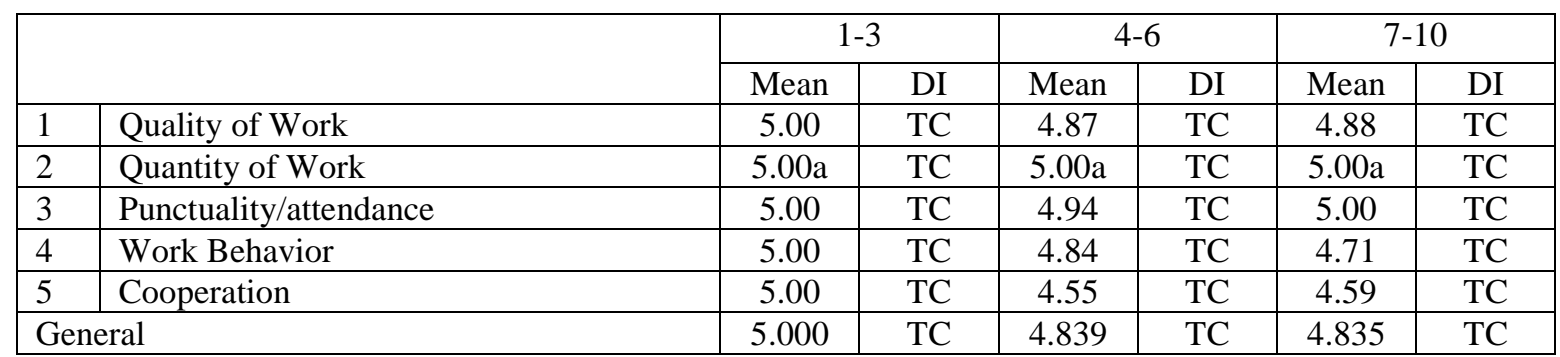

Legend: TC - Tremendous Contribution a. F cannot be computed because the standard deviations of both groups are 0 .

Table 13. Role of Non-financial Incentive Program as to Number of Employees

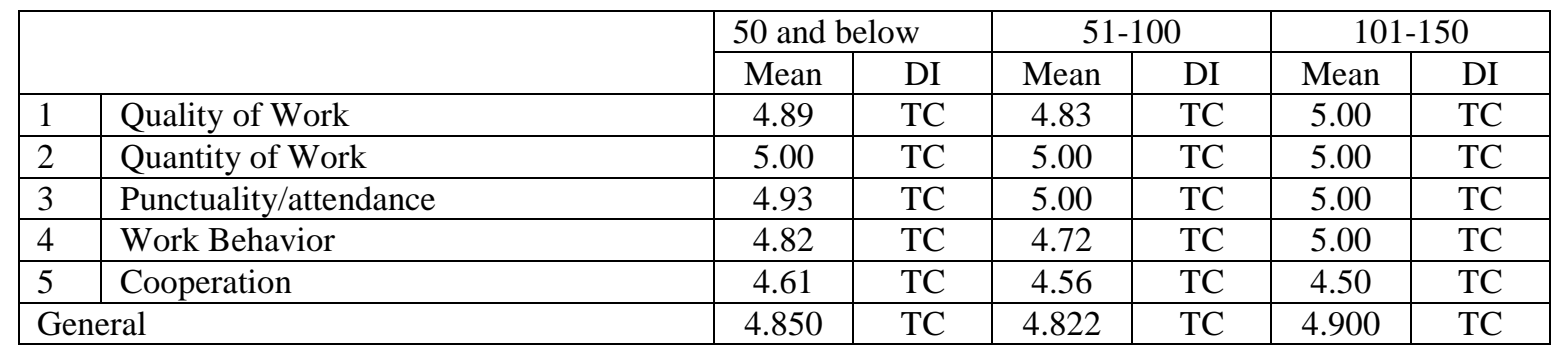

Legend: TC - Tremendous Contribution a. F cannot be computed because the standard deviations of both groups are 0 .

Table 14. Role of Financial Incentive Program as to Sex

\begin{tabular}{|l|l|c|c|c|c|}
\hline \multicolumn{2}{|c|}{} & \multicolumn{2}{c|}{ Male } & \multicolumn{2}{c|}{ Female } \\
\cline { 3 - 6 } \multicolumn{2}{|c|}{} & Mean & DI & Mean & DI \\
\hline 1 & Quality of Work & 3.00 & MC & 2.81 & MC \\
\hline 2 & Quantity of Work & 3.00 & MC & 3.00 & MC \\
\hline 3 & Punctuality/attendance & 3.00 & MC & 3.06 & MC \\
\hline 4 & Work Behavior & 2.84 & MC & 3.13 & MC \\
\hline 5 & Cooperation & 3.26 & MC & 2.94 & MC \\
\hline \multicolumn{2}{|l|}{ Average } & 3.021 & MC & 2.987 & MC \\
\hline
\end{tabular}

Legend: MC - Moderate Contribution

Table 15. Role of Financial Incentive Program as to Age

\begin{tabular}{|l|l|c|c|c|c|c|c|}
\hline \multicolumn{2}{|c|}{} & \multicolumn{2}{|c|}{$26-35$} & \multicolumn{2}{c|}{$36-45$} & \multicolumn{2}{c|}{$46-55$} \\
\cline { 3 - 8 } & Qean & DI & Mean & DI & Mean & DI \\
\hline 1 & Quality of Work & 3.00 & MC & 2.92 & MC & 2.75 & MC \\
\hline 2 & Quantity of Work & 3.00 & MC & 3.00 & MC & 3.00 & MC \\
\hline 3 & Punctuality/attendance & 3.00 & MC & 3.12 & MC & 2.94 & MC \\
\hline 4 & Work Behavior & 3.44 & MC & 3.08 & MC & 2.69 & MC \\
\hline 5 & Cooperation & 3.11 & MC & 3.20 & MC & 2.81 & MC \\
\hline \multicolumn{2}{|l|l|l|l|}{ General } & 3.111 & MC & 3.064 & MC & 2.838 & MC \\
\hline
\end{tabular}




\section{ISO 3297:2007 Certified}

Vol. 4, Issue 3, March 2017

Table 16. Role of Financial Incentive Program as to Educational Background

\begin{tabular}{|l|l|c|c|c|c|}
\hline \multicolumn{2}{|c|}{} & \multicolumn{2}{|c|}{ BS } & \multicolumn{2}{c|}{ MA } \\
\cline { 3 - 6 } & Quality of Work & 2.97 & DI & Mean & DI \\
\hline 1 & Quantity of Work & 3.00 & MC & 2.74 & MC \\
\hline 3 & Punctuality/attendance & 2.90 & MC & 3.00 & MC \\
\hline 4 & Work Behavior & 2.94 & MC & 3.16 & MC \\
\hline 5 & Cooperation & 3.06 & MC & 3.05 & MC \\
\hline \multicolumn{2}{|l|}{ Average } & 2.974 & MC & 3.042 & MC \\
\hline
\end{tabular}

Legend: MC - Moderate Contribution

Table 17. Role of Financial Incentive Program as to Position

\begin{tabular}{|l|l|c|c|c|c|}
\hline \multicolumn{2}{|c|}{} & \multicolumn{2}{|c|}{ Supervisor } & \multicolumn{2}{c|}{ Manager } \\
\cline { 3 - 6 } & Quality of Work & 2.93 & DI & Mean & DI \\
\hline 1 & Quantity of Work & 2.79 & MC & 2.81 & MC \\
\hline 2 & Punctuality/attendance & 3.00 & MC & 3.10 & MC \\
\hline 3 & Work Behavior & 3.07 & MC & 2.95 & MC \\
\hline 4 & Wor & 3.17 & MC & 2.90 & MC \\
\hline 5 & Cooperation & 2.993 & MC & 3.010 & MC \\
\hline \multicolumn{2}{|l|}{ Average }
\end{tabular}

Legend: MC - Moderate Contribution

Table 18. Role of Financial Incentive Program as to Number of Years

\begin{tabular}{|l|l|c|c|c|c|c|c|}
\hline \multicolumn{2}{|c|}{} & \multicolumn{2}{|c|}{$1-3$} & \multicolumn{2}{c|}{$4-6$} & \multicolumn{2}{c|}{$7-10$} \\
\cline { 3 - 8 } \multicolumn{2}{|c|}{} & Mean & DI & Mean & DI & Mean & DI \\
\hline 1 & Quality of Work & 2.50 & MC & 2.84 & MC & 3.00 & MC \\
\hline 2 & Quantity of Work & 3.00 & MC & 2.94 & MC & 3.12 & MC \\
\hline 3 & Punctuality/attendance & 3.50 & CC & 3.10 & MC & 2.88 & MC \\
\hline 4 & Work Behavior & 3.50 & CC & 2.94 & MC & 3.12 & MC \\
\hline 5 & Cooperation & 2.00 & VLC & 3.10 & MC & 3.12 & MC \\
\hline General & 2.900 & MC & 2.981 & MC & 3.047 & MC \\
\hline
\end{tabular}

Legend: VLC - Very Little Contribution; MC - Moderate Contribution; CC - Considerable Contribution

Table 19. Role of Financial Incentive Program as to Number of Employees

\begin{tabular}{|l|l|c|c|c|c|c|c|}
\hline \multicolumn{2}{|c|}{} & \multicolumn{2}{|c|}{50 and below } & \multicolumn{2}{c|}{$51-100$} & \multicolumn{2}{c|}{$101-150$} \\
\cline { 3 - 8 } & Mean & DI & Mean & DI & Mean & DI \\
\hline 1 & Quality of Work & 2.86 & MC & 2.89 & MC & 3.00 & MC \\
\hline 2 & Quantity of Work & 3.04 & MC & 2.89 & MC & 3.25 & MC \\
\hline 3 & Punctuality/attendance & 3.04 & MC & 3.06 & MC & 3.00 & MC \\
\hline 4 & Work Behavior & 2.89 & MC & 3.17 & MC & 3.25 & MC \\
\hline 5 & Cooperation & 3.21 & MC & 2.78 & MC & 3.25 & MC \\
\hline General & 3.007 & MC & 2.956 & MC & 3.150 & MC \\
\hline
\end{tabular}

Legend: MC - Moderate Contribution

Table 20. Relationship between Incentive Program and Employee Performance

\begin{tabular}{|c|c|c|c|c|}
\hline \multicolumn{2}{|l|}{} & $\begin{array}{c}\text { General } \\
\text { Perception }\end{array}$ & $\begin{array}{c}\text { Non-financial } \\
\text { Incentive Program }\end{array}$ & $\begin{array}{c}\text { Financial Incentive } \\
\text { Program }\end{array}$ \\
\hline \multirow{3}{*}{ Employee Performance } & Pearson Correlation & $.300^{*}$ & $.797^{* *}$ & -.035 \\
\cline { 2 - 5 } & Sig. (2-tailed) & .034 & .000 & .809 \\
\cline { 2 - 5 } & $\mathrm{N}$ & 50 & 50 & 50 \\
\hline
\end{tabular}

\footnotetext{
*. Correlation is significant at the 0.05 level (2-tailed).
}

**. Correlation is significant at the 0.01 level (2-tailed). 